This is the final peer-reviewed accepted manuscript of

Sabia, Alessandra; Baldisserotto, Costanza; BIONDI, STEFANIA; Marchesini, Roberta; Tedeschi, Paola;

Maietti, Annalisa; Giovanardi, Martina; Ferroni, Lorenzo; Pancaldi, Simonetta: Re-cultivation of Neochloris oleoabundans in exhausted autotrophic and mixotrophic media: the potential role of polyamines and free fatty acids. APPLIED MICROBIOLOGY AND BIOTECHNOLOGY, 99. ISSN 0175-7598

DOI: $10.1007 / s 00253-015-6908-3$

The final published version is available online at:

http://dx.doi.org/10.1007/s00253-015-6908-3

Rights / License:

The terms and conditions for the reuse of this version of the manuscript are specified in the publishing policy. For all terms of use and more information see the publisher's website.

This item was downloaded from IRIS Università di Bologna (https://cris.unibo.it/)

When citing, please refer to the published version. 


\title{
Re-cultivation of Neochloris oleoabundans in exhausted autotrophic and mixotrophic media: the potential role of polyamines and free fatty acids
}

\author{
Alessandra Sabia ${ }^{1} \cdot$ Costanza Baldisserotto $^{1} \cdot$ Stefania Biondi $^{2} \cdot$ Roberta Marchesini $^{1}$. \\ Paola Tedeschi ${ }^{3}$ - Annalisa Maietti ${ }^{3}$ - Martina Giovanardi ${ }^{1}$ - Lorenzo Ferroni $^{1}$. \\ Simontta Pancaldi ${ }^{1}$
}

\begin{abstract}
Neochloris oleoabundans (Chlorophyta) is widely considered one of the most promising microalgae for biotechnological applications. However, the large-scale production of microalgae requires large amounts of water. In this perspective, the possibility of using exhausted growth media for the re-cultivation of $N$. oleoabundans was investigated in order to simultaneously make the cultivation more economically feasible and environmentally sustainable. Experiments were performed by testing the following media: autotrophic exhausted medium $(\mathrm{E}+)$ and mixotrophic exhausted medium after cultivation with glucose $(\mathrm{EG}+)$ of $N$. oleoabundans cells grown in a 20-L photobioreactor (PBR). Both exhausted media were replenished with the same amounts of nitrate and phosphate as the control brackish medium (C). Growth kinetics, nitrate and phosphate consumption, photosynthetic pigments content, photosynthetic efficiency, cell morphology, and lipid production were evaluated. Moreover, the free fatty acid (FFA) composition of exhausted media and the polyamine (PA) concentrations of both algae and media were analyzed in order to test if some molecules, released into the medium, could influence algal growth and metabolism. Results showed that
\end{abstract}

Simonetta Pancaldi

simonetta.pancaldi@unife.it

1 Department of Life Sciences and Biotechnology, University of Ferrara, Corso Ercole I d'Este 32, 44121 Ferrara, Italy

2 Department of Biological, Geological and Environmental Sciences, University of Bologna, via Irnerio 42, 40126 Bologna, Italy

3 Department of Chemical and Pharmaceutical Science, University of Ferrara, via Fossato di Mortara 17, 44121 Ferrara, Italy
$N$. oleoabundans can efficiently grow in both exhausted media, if appropriately replenished with the main nutrients (E+ and $\mathrm{EG}+$ ), especially in $\mathrm{E}+$ and to the same extent as in $\mathrm{C}$ medium. Growth promotion of $N$. oleoabundans was attributed to PAs and alteration of the photosynthetic apparatus to FFAs. Taken together, results show that recycling growth medium is a suitable solution to obtain good $N$. oleoabundans biomass concentrations, while providing a more sustainable ecological impact on water resources.

Keywords Neochloris oleoabundans · Recycling culture media Photosynthetic apparatus · Biomass production . Polyamines $\cdot$ Free fatty acids

\section{Introduction}

Over the last decades, microalgae have received much attention as a promising high-potential feedstock for biodiesel (Chisti 2007; Li et al. 2008; Borowitzka and Moheimani 2013) and as an attractive raw material for the production of a wide range of high-value bioproducts (Molina Grima et al. 2003; Mata et al. 2010). They are photosynthetic microorganisms with numerous key features, which potentially make them a more appreciable renewable source than terrestrial plants (Richmond 2004; $\mathrm{Hu}$ et al. 2008; Ndimba et al. 2013). For instance, these microorganisms have faster growth rates, higher photosynthetic efficiencies, higher rates of carbon dioxide fixation, and higher biomass productivities compared with plants (Richmond 2004; Gouveia et al. 2009; Harun et al. 2010; Mata et al. 2010). Moreover, microalgae can thrive in non-arable lands being able to grow in waters having different salinity levels and chemical composition (Smith et al. 2010; Borowitzka and Moheimani 2013). 
The environmental and economical impact of large-scale production of microalgae has been widely discussed, with the aim of making the process increasingly sustainable (Sheehan 2009; Solomon 2010). In this perspective, microalgal cultivation systems are crucial factors to be taken into account (Smith et al. 2010; Stephens et al. 2010; Borowitzka and Moheimani 2013). A wide variety of systems has been described by Mata et al. (2010) and recently by Borowitzka and Moheimani (2013). Microalgae can be cultivated in open pond reactors or closed photobioreactors (PBRs), depending on algal strain, issue of research, type of desired products, and environmental conditions (Chisti 2007; Mata et al. 2010; Borowitzka and Moheimani 2013). Although open ponds are the most commonly used culture systems, due to their low cost of production and operation, recently closed PBRs are receiving much attention for the possibility of producing valuable compounds (Pulz 2001; Grobbelaar 2009; Smith et al. 2010). However, algal cultures require large amounts of water in both culture systems (Lam and Lee 2012; Borowitzka and Moheimani 2013). Considering that water is becoming a scarce natural resource, water demand represents an important factor when performing large-scale cultivation (Batan et al. 2013; Farooq et al. 2014). In order to reduce the high production costs and, at the same time, to make microalgal production more environmentally sustainable, recycling culture medium has been proposed as a possible solution (Yang et al. 2011; HadjRomdhane et al. 2012; Farooq et al. 2014), especially in large-scale culture systems (Borowitzka 2005; Lam and Lee 2012; Zhu et al. 2013). However, the feasibility of recycling growth medium to re-cultivate microalgae has been tested only in a few cases (Lívanský et al. 1996; Rodolfi et al. 2003; Hadj-Romdhane et al. 2013; Zhu et al. 2013). It is reported that the recycling medium could have negative ef-fects on biomass productivity, due to the release of inhibitory secondary metabolites (Richmond 2004). Harmful metabo-lites are, in fact, released during microalgal growth under physiological stress (Ikawa 2004; Moheimani and Borowitzka 2006). Free fatty acids (FFAs), and substances derived from the photooxidation of unsaturated fatty acids, are the most common metabolites with inhibitory effects on microalgae (Ikawa 2004; Wu et al. 2006; Bosma et al. 2008; Stephens et al. 2010).

In the present work, the suitability of recycling growth media for the re-cultivation of Neochloris oleoabundans (Chlorophyta) was investigated. This species was chosen because it is considered one of the most promising oil-rich microalgae, due to its capability to accumulate lipids when grown under nitrogen starvation (Tornabene et al. 1983; Chisti 2007; Li et al. 2008; Pruvost et al. 2009) or mixotrophically, in the presence of glucose, or carbon-rich wastes, as organic carbon sources (Giovanardi et al. 2013; Baldisserotto et al. 2014). Present results clearly indicate that $N$. oleoabundans can efficiently grow in its exhausted growth medium, if suitably replenished with the main nutrients. Based on this encouraging result, and with the aim of gaining further knowledge on the morpho-physiological aspects and biotechnological applications of this algal strain, the following features were analyzed: (1) growth kinetics in parallel to nitrate and phosphate consumption; (2) photosynthetic pigment content; (3) PSII maximum quantum yield; (4) cell morphology, with special attention to intracellular lipid accumulation,(5) FFA accumulation in recycled growth media, and (6) poly-amine (PA) concentration both inside cells and in the corre-sponding culture media. PAs were determined in order to un-derstand if these plant growth regulators could be responsible for the growth promotion of $N$. oleoabundans in recycled growth medium. It is known, in fact, that PAs, together with other plant growth regulators, have stimulatory effects on al-gal growth and metabolism, and are involved in mitigating various types of biotic and abiotic stress (Tate et al. 2013).

\section{Materials and methods}

\section{Algal strains and culture condition}

The strain used in this study was the Chlorophyta $N$. oleoabundans UTEX 1185 (syn. Ettlia oleoabundans) (Sphaeropleales, Neochloridaceae), obtained from the Culture Collection of Algae of the University of Texas (UTEX, Austin, Texas, USA; www.utex.org).

$N$. oleoabundans was cultivated in axenic liquid brackish medium (BM) (Baldisserotto et al. 2012) in a coaxial 20-L capacity PBR (M2M Engineering, Grazzanise, Caserta, Italy). Algae were cultivated autotrophically in BM for 25 days or mixotrophically, by addition of $2.5 \mathrm{~g} \mathrm{~L}^{1}$ glucose, for 8 days, according to previously described protocols (Baldisserotto et al. 2014; Giovanardi et al. 2014). For autotrophic cultivation, cells were inoculated into the PBR to ob-tain an initial cell density of about $0.6 \times 10^{6}$ cells $\mathrm{mL}^{1}$, while for mixotrophic cultivation initial cell density was higher $\left(10 \times 10^{6}\right.$ cells $\mathrm{mL}^{1}$ ). Culture conditions in the PBR were $24 \pm 1{ }^{\circ} \mathrm{C}$; sterile air injection at the bottom of the PBR, with $0.5 / 3.5 \mathrm{~h}$ bubbling/static cycles; irradiance $65 \mu_{\mathrm{mol}_{\text {photons }} \mathrm{m}}$ ${ }^{2} \mathrm{~s}{ }^{1}$ of PAR (16:8 h light/dark photoperi-od). Light was supplied with inner cool-white fluorescent Philips tubes.

Algal growth and morphology in the PBR were monitored as described below.

\section{Preparation of growth media}

Experiments were performed by testing the following media:

C Freshly prepared BM medium (control);

E Autotrophic exhausted medium; 
EG Mixotrophic exhausted medium after cultivation with glucose;

E+ Autotrophic exhausted medium replenished with nitrate and phosphate concentrations as for BM medium;

EG+ Mixotrophic exhausted medium after cultivation with glucose and replenished with nutrients as in $\mathrm{E}+$.

In order to obtain the exhausted media for the recycling experiment, $N$. oleoabundans was grown inside the PBR under the culture conditions described in the previous section. For E+ medium preparation, about $500 \mathrm{~mL}$ of autotrophic algal culture in the stationary phase of growth (at the 15 th day of cultivation in the PBR) were centrifuged at $2000 \times g$ for $10 \mathrm{~min}$ in order to separate the medium from the algae, thus obtaining an autotrophic exhausted medium (E). The medium appeared pale-yellow and was free from algae, bacteria, and protozoa; its optical density at a wavelength of $750 \mathrm{~nm}\left(\mathrm{OD}_{750}\right)$ was 0.02 . For EG+ medium, at the 8 th day of cultivation in the PBR, the same aliquots of algal culture were harvested by centrifugation $(2000 \times g$ for $10 \mathrm{~min})$. In this case, the mixotrophic exhausted medium (EG) was straw-yellow in color and presented a weak bacterial contamination due to the glucose addition $\left(\mathrm{OD}_{750}=0.009\right)$. Glucose was proved to be totally consumed during the previous cultivation inside the PBR by 3,5-dinitrosalicylic (DNS; Sigma-Aldrich, Gallarate, Milan, Italy) acid assay, according to Giovanardi et al. (2014). In both exhausted media, $\mathrm{pH}$ was not adjusted. After determining the nitrate and phosphate concentrations of the two exhausted media (see "Nitrate and phosphate analyses"), $\mathrm{KNO}_{3}$ and $\mathrm{K}_{2} \mathrm{HPO}_{4}$ were axenically added to reach final concentrations of 0.2 and $0.02 \mathrm{~g} \mathrm{~L}^{1}$, respectively, i.e., the typical concentration of those components in $\mathrm{BM}$, thus obtaining the replenished exhausted media (E+ and $\mathrm{EG}+$ ) used for experiments.

\section{Experimental design}

When autotrophic cultures of $N$. oleoabundans, grown in $\mathrm{BM}$ in the $\mathrm{PBR}$, reached a cell density of $10 \times$ $10^{6}$ cells $\mathrm{mL}^{1}$ (after about 9 days of cultivation), aliquots of cells were inoculated into 300-mL Erlenmeyer flasks (150 $\mathrm{mL}$ total volume) containing $\mathrm{C}, \mathrm{E}+$, or $\mathrm{EG}+$ media, to obtain an initial cell density of about $0.5 \times 10^{6}$ cells $\mathrm{mL}{ }^{1}$. The cultures were placed in a growth chamber $\quad\left(24 \pm 1^{\circ}\right.$ C, $80 \mu \mathrm{mol}_{\text {photons }} \mathrm{m}^{2} \mathrm{~s}^{1}$ of PAR with a 16:8 h light/ darkness photoperiod) and cultivated with continuous shaking at $80 \mathrm{rpm}$, without external $\mathrm{CO}_{2}$ supply. Experiments were performed in triplicate. Aliquots of cultures (cells and me-dia) were collected at different times of cultivation up to 25 days, depending on the analysis.

\section{Analyses}

\section{Growth evaluation}

Aliquots of cell samples cultivated in control and exhausted media were counted at $0,3,7,12,17$, and 25 days of cultivation using a Thoma hemocytometer (HBG, Giessen, Germany) under a light microscope (Zeiss, model Axiophot), and growth curves were obtained.

The growth rate ( $\mu$, number of divisions per day) during the exponential phase was calculated with the following equation:

$\mu\left(\operatorname{div} \operatorname{day}^{1}\right)=\left(\log _{2} \mathrm{~N}_{1}-\log _{2} \mathrm{~N}_{0}\right) /\left(\mathrm{t}_{1}-\mathrm{t}_{0}\right)$,

where $\mu$ is the growth rate, $N_{1}$ the cell number at time $t_{1}, N_{0}$ the cell number at time 0 , and $t_{1}-t_{0}$ the time interval (days) (Giovanardi et al. 2013).

In parallel to growth, $\mathrm{pH}$ was also periodically monitored on small aliquots of samples.

\section{Nitrate and phosphate analyses}

After 12 and 25 days of cultivation, samples of $\mathrm{C}, \mathrm{E}+$, and $\mathrm{EG}+$ media were harvested by centrifugation to analyze nitrate and phosphate concentrations. These nutrients were quantified colorimetrically using a flow-injection autoanalyzer (FlowSys, Systea, Roma, Italy).

\section{Photosynthetic pigment extraction and quantification}

For photosynthetic pigment analysis, cell samples were col-lected by centrifugation after $0,7,17,21$, and 25 days of cultivation. Extraction of photosynthetic pigments was per-formed according to Baldisserotto et al. (2014). The extracts were measured with a Pharmacia Ultrospec 2000 UV-Vis spectrophotometer (1-nm bandwidth; Amersham Biosciences, Piscataway, NJ, USA) at 666 (chlorophyll $a(\mathrm{Chl} a)$ ), 653 (chlorophyll $b(\mathrm{Chl} b)$ ), and 470 $\mathrm{nm}$ (carotenoids (Car)). Quantification was performed according to equations reported in Wellburn (1994).

\section{PAM fluorimetry}

The PSII maximum quantum yield of algae was determined at the same cultivation times considered for growth kinetics measurements. A pulse amplitude-modulated fluorometer (ADC Bioscientific Ltd., Hoddesdon, Hertfordshire, UK) was used to determine the in vivo chlorophyll fluorescence of PSII. The PSII maximum quantum yield is reported as $F_{\mathrm{V}} /$ $F_{\mathrm{M}}$ ratio, i.e., $\left(F_{\mathrm{M}}-F_{0}\right) / F_{\mathrm{M}}$, where variable fluorescence is $F_{\mathrm{V}}=\left(F_{\mathrm{M}}-F_{0}\right), F_{\mathrm{M}}$ is the maximum fluorescence and $F_{0}$ is the initial fluorescence of samples (Lichtenthaler et al. 2005). This measurement is considered a valid method to probe the 
maximum quantum yield of photochemistry in PSII (Kalaji et al. 2014). Moreover, it is useful to estimate the physiological state of plants and microorganisms also under nutrient stress (White et al. 2011). Samples were prepared as reported in Ferroni et al. (2011) after 15 min of dark incubation.

\section{Light and fluorescence microscopy}

For microscopic observations, cell samples were routinely collected throughout the cultivation period inside the PBR and during the experiment with exhausted media. Aliquots of samples were observed using a microscope (Zeiss, model Axiophot) with conventional and fluorescent attachments. The light source for chlorophyll fluorescence observation was a HBO $100 \mathrm{~W}$ pressure mercury vapor lamp (filter set, BP436/10, LP470). Pictures of cells were taken with a Canon IXUS 110 IS digital camera (12.1 megapixels), mounted on the ocular lens through a Leica DC150 system (Leica Camera AG, Solms, Germany).

\section{Lipid staining}

During experiments, the intracellular presence of lipids was evaluated by staining cells with the fluorochrome Nile red (9diethylamina- $5 \mathrm{Hbenzo}[\alpha]$ phenoxazine-5-one, $0.5 \mathrm{mg}$ dissolved in $100 \mathrm{~mL}$ acetone; Sigma-Aldrich, Gallarate, Milan, Italy), as described in Giovanardi et al. (2014). After incubation at $37{ }^{\circ} \mathrm{C}$ in darkness for $15 \mathrm{~min}$, cells were observed with the microscope described above at an excitation wavelength of $485 \mathrm{~nm}$ (filter set, BP485, LP520). Photographs were taken with the camera described above.

\section{Transmission electron microscopy}

Transmission electron microscopy (TEM) observations were made on cells harvested by centrifugation $(600 \times g, 10 \mathrm{~min})$ at the 12th day of cultivation. Cells were fixed, post-fixed, and dehydrated as reported in Baldisserotto et al. (2012). Embedding in resin and staining procedures were performed as previously described (Pancaldi et al. 2002). Sections were observed with a Hitachi H800 electron microscope (Hitachi, Tokyo, Japan) at the Electron Microscopy Centre, University of Ferrara.

\section{Extracellular free fatty acids analysis}

To analyze the FFA composition of the exhausted E and EG media used to prepare $\mathrm{E}+$ and $\mathrm{EG}+$ replenished media, al-iquots of $N$. oleoabundans cultures grown autotrophically and mixotrophically in the PBR were collected at the 15th and at the 8th days of cultivation, respectively. Samples were centrifuged at $2000 \times \mathrm{g}$ for $10 \mathrm{~min}$ in order to separate the medium from algae. Fifty milliliters of media obtained from the autotrophic (E) and mixotrophic (EG) cultures were freeze-dried for analysis. The extracellular FFA composition $w$ as determined in duplicate $b$ y $g$ as chromatography-mass spectrometry (GC-MS). For extrac-tion, samples were dissolved in $3 \mathrm{~mL}$ of hexane, sonicated for $15 \mathrm{~min}$, and extracted overnight. Fatty acid methyl es-ters were prepared by transesterification with 1.5 $\mathrm{mL}$ of $5 \%$ of sodium hydroxide in methanol solution. Sample volumes of $1 \mu \mathrm{L}$ were injected into the GC-MS apparatus, which consisted of a Varian Saturn $2100 \mathrm{MS} /$ MS ion trap mass spectrometer. Separations were performed using a Zebron ZB-WAX Phenomenex capillary column $(60 \mathrm{~cm}$ in length, $0.25 \mathrm{~mm}$ i.d.) supplied with helium carrier gas at $1 \mathrm{~mL}$ min ${ }^{1}$ constant flow. The injector temperature was $250^{\circ} \mathrm{C}$, and the oven temperature program was the follow-ing: start $100{ }^{\circ} \mathrm{C}$ for $2 \mathrm{~min}$, ramp to $200{ }^{\circ} \mathrm{C}$ at $10{ }^{\circ} \mathrm{C} / \mathrm{min}$, and hold for $108 \mathrm{~min}$. The MS acquisitions were performed by full-scan mode.

\section{Determination of polyamines}

To analyze the free PA composition of $N$. oleoabundans cells cultivated autotrophically and mixotrophically in PBR and in the corresponding E and EG media, samples were collected as described for FFA analyses. Freeze-dried E or EG media and algae (50 and $20 \mathrm{mg}$, respectively) were extracted in cold $4 \%$ perchloric acid, kept for $1 \mathrm{~h}$ on ice, and then centrifuged at $15,000 \times \mathrm{g}$ for $15 \mathrm{~min}$. Aliquots $(200 \mu \mathrm{L})$ of the supernatants and standard solutions of putrescine (Put), spermidine (Spd), and spermine (Spm) were derivatized with dansyl chloride (Scaramagli et al. 1999). Dansylated derivatives were extracted with toluene, taken to dryness and resuspended in acetonitrile. PAs were separated and quantified by HPLC using a reverse-phase $\mathrm{C}_{18}$ column (Spherisorb ODS2, 5- $\mu \mathrm{m}$ particle diameter, $4.6 \times 250 \mathrm{~mm}$, Waters, Wexford, Ireland) and a programmed acetonitrile/water step gradient (flow rate, $1 \mathrm{~mL}$ min ${ }^{1}$ ) on a Jasco system (Jasco Corp., Tokyo, Japan) consisting of a PU-1580 pump, an LG-1580-02 ternary gradient unit, a DG-1580-53 three-line degasser, and a FP-1529 fluorescence detector, linked to an autosampler (AS 2055 Plus).

\section{Data analysis}

Data were processed with Graphpad Prism 6 (Graph Pad Software, San Diego CA, USA). In each case, means \pm standard deviations for $n$ number of samples are given. Statistical analyses for comparison of means were car-ried out using ANOVA, followed by Student's $t$ test (signifi-cance level, 0.05). 


\section{Results}

\section{Growth and morphology of $N$. oleoabundans cultivated autotrophically and mixotrophically in a 20-L PBR}

Growth kinetics and cell morphology of $N$. oleoabundans cul-tivated autotrophically and mixotrophically in a $20-\mathrm{L}$ PBR are shown in Fig. 1. Autotrophic cells rapidly entered the expo-nential phase starting on the 2nd-3rd day up to the 7th-9th day of cultivation (Fig. 1a). After this period, cultures had a short late exponential phase and then entered the stationary phase of growth, reaching a final cell density of about $22 \times 10^{6}$ cells $\mathrm{mL}^{1}$ at the end of the of cultivation time (25 days). During the entire period, cells showed the typical morphology of $N$. oleoabundans grown in BM medium, i.e., almost spher-ical, with a cell diameter of 3-5 $\mu \mathrm{m}$ (Fig. 1b, d). One cup-shaped chloroplast, containing a large pyrenoid, was present and emitted an intense red fluorescence due to the presence of chlorophyll (Fig. 1b, c). On the 25th day of cultivation, cells maintained their normal features and dimensions, but accumu-lated some lipid globules inside the cytoplasm, as revealed by Nile red staining (Fig. 1d, e).
During the first 4 days of mixotrophic growth in the PBR in the presence of glucose, cells showed an evident increase in cell density, reaching values of ca. $33 \times 10^{6}$ cells $\mathrm{mL}^{1}$ (Fig. 1f). Subsequently, cells entered the stationary phase of growth, and then cell density leveled off to values of about $36 \times$ $10^{6}$ cells $\mathrm{mL}^{1}$ up to the end of the cultivation period, i.e., 8 days. At the beginning of cultivation, both cell shape and size, and chloroplast features in mixotrophic cultures (Fig. 1g, h) were similar to those of autotrophic cultures (Fig. 1b, c). Starting on the 3rd day and up to the end of cultivation, however, mixotrophic cells showed peculiar features. In fact, the chloroplast lost its characteristic cup shape and translucent globules, which tended to occupy almost the entire cell volume, accumulated inside the cytoplasm (Fig. 1i). Nile red staining confirmed the lipidic nature of these droplets (Fig. 1j).

\section{Extracellular FFA composition in E and EG media}

The extracellular FFA composition in the exhausted autotrophic (E) and mixotrophic (EG) media of $N$. oleoabundans is shown in Table 1. While EG medium comprised both
Fig. 1 a e Growth kinetics (a) and morphology (b e) of Neochloris oleoabundans cells autotrophically cultivated in a 20 L PBR in BM medium. Light (b, d) and fluorescence microscope observations $(\mathbf{c}, \mathbf{e})$ of $N$. oleoabundans cells after 3 days $(\mathbf{b}, \mathbf{c})$ and 25 days $(\mathbf{d}, \mathbf{e})$ of autotrophic cultivation. $\mathbf{f} \mathbf{j}$ Growth kinetics (f) and cell morphology ( $\mathbf{g} \mathbf{j})$ of $N$. oleoabundans cultivated in a 20 L PBR in BM medium under mixotrophic conditions (supplemented with $2.5 \mathrm{~g} \mathrm{~L}^{1}$ of glucose). Light (g, i) and fluorescence microscope observations $(\mathbf{h}, \mathbf{j})$ of $N$. oleoabundans cells after 3 days $(\mathbf{g}, \mathbf{h})$ and 8 days $(\mathbf{i}, \mathbf{j})$ of mixotrophic cultivation. In both graphs, curves are constructed on a $\log _{2}$ scale and data are means $\pm \operatorname{SD}(n=3)$. In all micrographs, bars $=2 \mu \mathrm{m}$
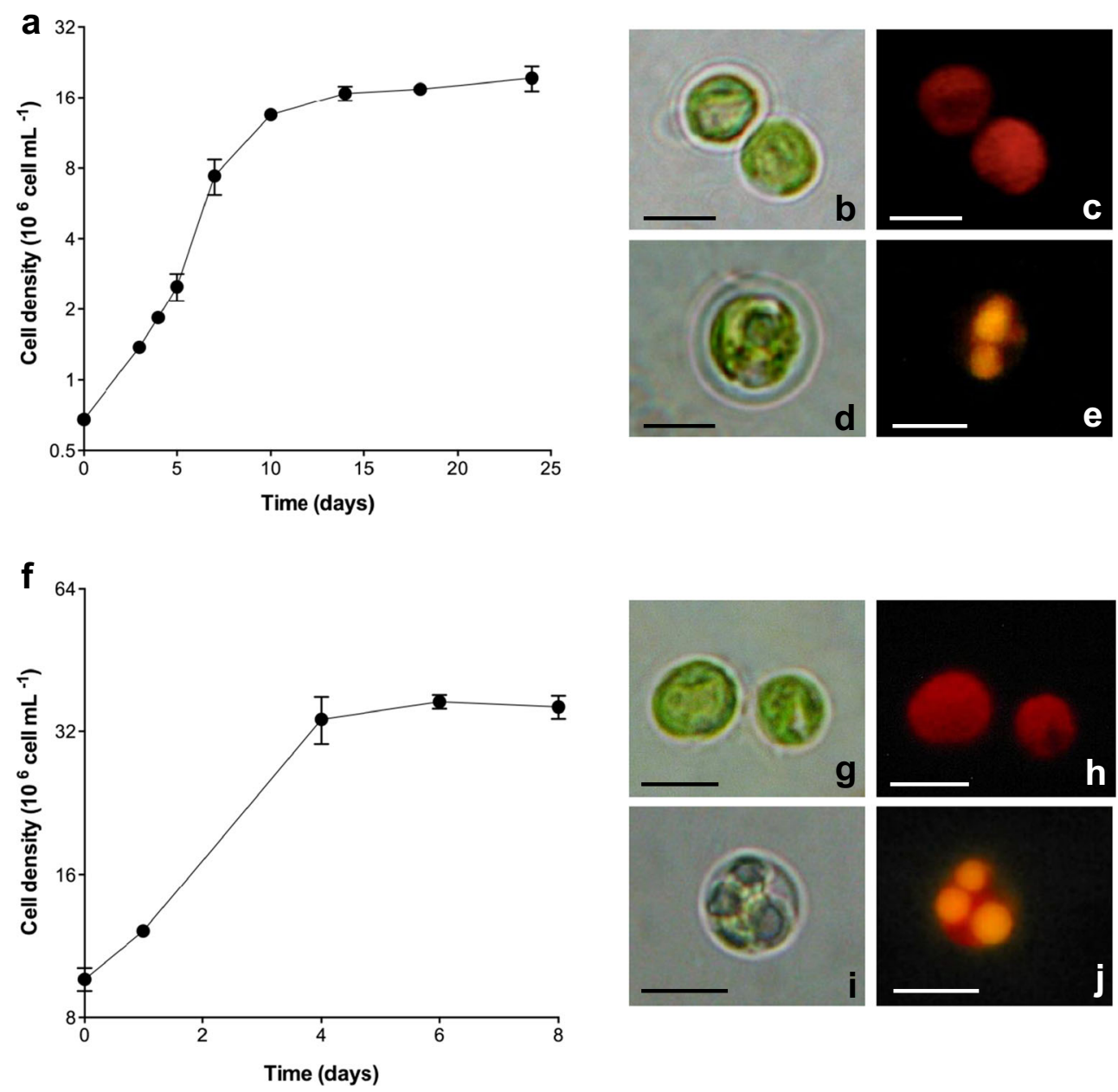
Table 1 Extracellular free fatty acids composition in the exhausted $\mathrm{E}$ and EG media of Neochloris oleoabundans grown in 20 L PBR, after 15 and 8 days of cultivation, respectively

\begin{tabular}{lllr}
\hline Fatty acids & Abbreviation & E medium & EG medium \\
\hline Myristic acid & C14:0 & $2.16 \pm 0.09$ & $2.09 \pm 0.04$ \\
Palmitic acid & C16:0 & $33.54 \pm 0.01$ & $34.43 \pm 2.80$ \\
Stearic acid & C18:0 & $64.31 \pm 0.10$ & $56.56 \pm 2.71$ \\
Oleic acid & C18:1 $\omega 9$ & nd & $5.93 \pm 1.47$ \\
\hline
\end{tabular}

Values are expressed as percentage of total fatty acids and are means \pm SD $(n=2)$

saturated and mono-unsaturated FFAs, E medium contained only saturated FFAs. In fact, both samples contained similar percentages of saturated myristic acid (C14:0) and palmitic acid (C16:0), while the percentage of stearic acid (C18:0) was different between the two samples. In E medium, stearic acid was present at about $64 \%$, while in EG medium at about $56 \%$; however, C18:0 represented the main saturated FFA for both samples. It is noteworthy that only EG medium

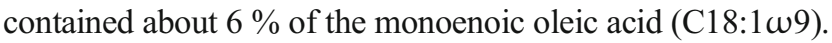

\section{Polyamine content in E and EG media} and in the corresponding $N$. oleoabundans cells cultivated in a 20- $\mathrm{L}$ PBR

As shown in Fig. 2a, the PA composition of $N$. oleoabundans cells cultivated mixotrophically in the PBR were characterized by higher putrescine, spermine, and, especially, spermidine levels compared with cells cultivated autotrophically. In fact, Spm, Put, and Spd concentrations in mixotrophic cells were ca. 2, 30, and 57 times higher, respectively, than those found in autotrophic cells $(p<0.001)$. Conversely, the PA composition in $\mathrm{E}$ and $\mathrm{EG}$ medium was not significantly different. In fact, both media contained similar amounts of Put and Spm. Interestingly, spermidine was present in high concentration in both media $\left(119 \pm 16.91\right.$ and $101 \pm 5.00 \mathrm{pmol} \mathrm{mL}^{1}$ in $\mathrm{E}$ and EG, respectively; Fig. 2b).

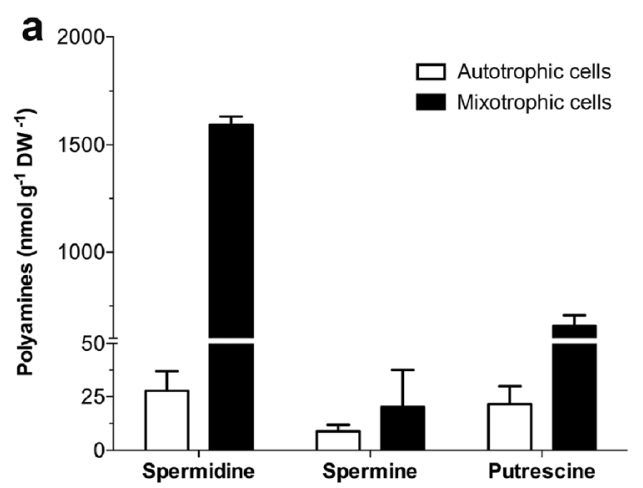

Fig. 2 Polyamine concentrations a in Neochloris oleoabundans cells cultivated in a 20 L PBR autotrophically and mixotrophically at 15 and 8 days of cultivation, respectively, and $\mathbf{b}$ in the corresponding exhausted

\section{Growth kinetics of $N$. oleoabundans in exhausted and control growth media}

As shown in Fig. 3a, the growth of $N$. oleoabundans in E+ medium was promoted for the entire experiment relative to controls grown on BM medium; on the contrary, growth in EG+ medium was similar to that of the C. All samples entered the exponential phase very soon (during the first 3 days of cultivation), despite some differences in growth rates (Fig. $3 b)$. The highest $\mu$ values were observed for algae culti-vated in the two exhausted media (E+ and $\mathrm{EG}+, 1.29$ and 1.18 div day ${ }^{1}$, respectively; control, 0.98 div day ${ }^{1} ; p<0.01$ in both cases relative to C) (Fig. 3b). Subsequently, from the 3rd day onwards, no relevant differences were observed between $\mathrm{C}$ and $\mathrm{EG}+$ samples, as both of them showed similar growth kinetics and cell densities (Fig. 3a). Conversely, E+ samples reached and maintained the highest cell density; the major dif-ference as compared with the other samples was observed starting on the 7 th day, with a cell density of about $16 \times 10^{6}$ cells $\mathrm{mL}^{1}$ (45 and $50 \%$ more than EG+ and $\mathrm{C}$ samples, respectively; $p<0.01$ in both cases relative to $\mathrm{E}$ + samples) at the same time point. After the 17th day, all samples entered the stationary phase, reaching, at the end of the experiment, a final cell density of $25-30 \times 10^{6}$ cells $\mathrm{mL}{ }^{1}$. During the experiments, aliquots of samples were periodically harvested to measure the $\mathrm{pH}$ of the culture media. As observed in the Electronic supple-mentary material (Fig. S1), initial $\mathrm{pH}$ was very different between control medium (about 7.0) and exhausted media (about 9.5 in both cases). $\mathrm{pH}$ gradually increased up to 9.2 in the control medium, while in $\mathrm{E}^{+}$and $\mathrm{EG}^{+}$media, the $\mathrm{pH}$ varied between 9.5 and 8.0 without any obvious trend.

\section{Consumption of nitrate and phosphate by $N$. oleoabundans cultivated in exhausted and control growth media}

The consumption of nitrate and phosphate by $N$. oleoabundans cells in the course of the experiment is depicted in Fig. 4. At

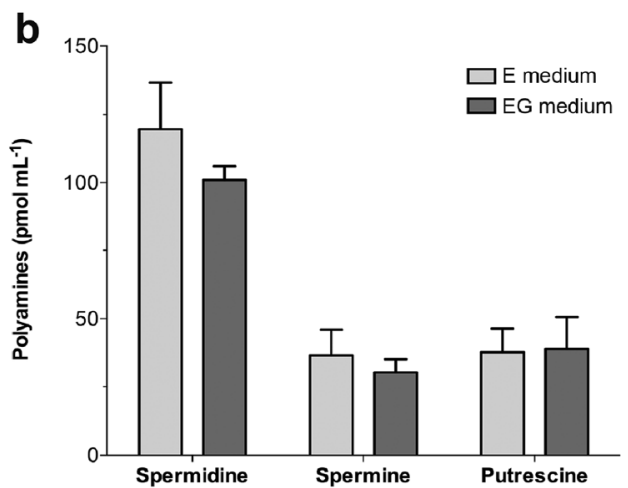

$\mathrm{E}$ and EG growth media. Autotrophic cells (white), mixotrophic cells (dark), E+ (light gray), and EG+ medium (dark gray). Values are means $\pm \mathrm{SD}(n=3)$ 
Fig. 3 a Growth kinetics of Neochloris oleoabundans in BM medium (filled circles), E+ medium (empty squares), and $\mathrm{EG}+$ medium (empty diamonds). b Growth rates, calculated during the exponential phase $\left(\begin{array}{lll}0 & 3 & \text { days }\end{array}\right.$ time interval of cultivation), of cells grown in $\mathrm{BM}$ (white), $\mathrm{E}+$ (light gray), and $\mathrm{EG}+$ (dark gray) media. The growth curve is constructed on a $\log _{2}$ scale, and data are means $\pm \mathrm{SD}(n=3)$

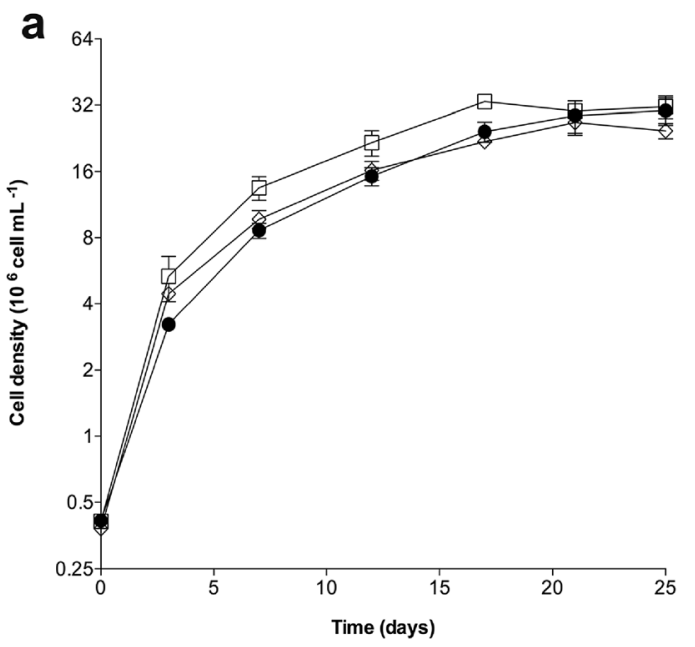

b

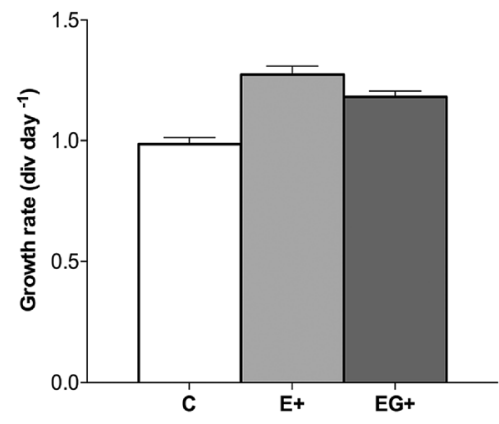

time 0 (inoculation), the exhausted replenished growth media contained approximately $2 \mathrm{mM} \mathrm{NO}_{3}$ and $0.115 \mathrm{mM} \mathrm{PO}_{4}{ }^{2}$, i.e., the typical concentration of those components in $\mathrm{BM}$ medium. By the end of the experiment, cells had consumed practically all nitrate and phosphate present in the growth media. However, nutrient consumption by $\mathrm{C}, \mathrm{E}+$, and $\mathrm{EG}+$ algal cultures followed different trends, since $\mathrm{C}$ samples maintained higher nitrate and phosphate concentrations than samples in exhausted media. In fact, after 12 days of cultivation, cells grown in $\mathrm{E}+$ and $\mathrm{EG}+$ had consumed about 34 and $68 \%$ of nitrate, respectively, while C only $15 \%$. Nitrate concentration decreased from $1.43 \mathrm{mM}$ at time 0 for all culture media to $0.94 \mathrm{mM}$ for $\mathrm{E}+, 0.45 \mathrm{mM}$ for $\mathrm{EG}^{+}$, and $1.21 \mathrm{mM}$ for $\mathrm{C}$ media ( $p<0.001$ in both treated samples relative to C; Fig. 4a). Differently, during the first 12 days of growth, phosphate exhibited a dramatic decrease, with a reduction by cells cultivated in EG+ and E+ of 94 and $98 \%$, respectively, while in C medium it was only about $60 \%$. In fact, phosphate concentration decreased from about $0.086 \mathrm{mM}$ at time 0 for all culture media to 0.002 for $\mathrm{E}+, 0.005$ for $\mathrm{EG}+$, and $0.035 \mathrm{mM}$ for $\mathrm{C}$ media $(p<$ 0.001 in both treated samples relative to $\mathrm{C}$; Fig. $4 \mathrm{~b}$ ).

\section{Photosynthetic pigment content in $N$. oleoabundans cultivated in exhausted and control media}

During the experiment, a gradual increase in photosynthetic pigment content was observed in all samples (Fig. 5). Chl $a$ in algae grown in $\mathrm{C}$ medium showed an evident increase up to the end of the experiment, reaching an average concentration of 0.5 nmol $10^{6}$ cells (Fig. 5a). A similar increasing trend was also observed in E+ samples, though with values 10-15\% low-er than those of controls. From the 17th day of cultivation, Chla content of $\mathrm{E}+$ samples was significantly lower than in $\mathrm{C}(32 \% ; p<0.01)$. Conversely, in EG+ samples, Chla content showed a slightly increasing trend as compared with $\mathrm{C}$ and $\mathrm{E}+$ samples; this led to a final value of $0.35 \mathrm{nmol} 10^{6}$ cells at the end of the experiment (32 and $21 \%$ lower than $\mathrm{C}$ and $\mathrm{E}+$ samples, respectively; Fig. 5a). An increasing trend in $\mathrm{Chl} b$ content was also
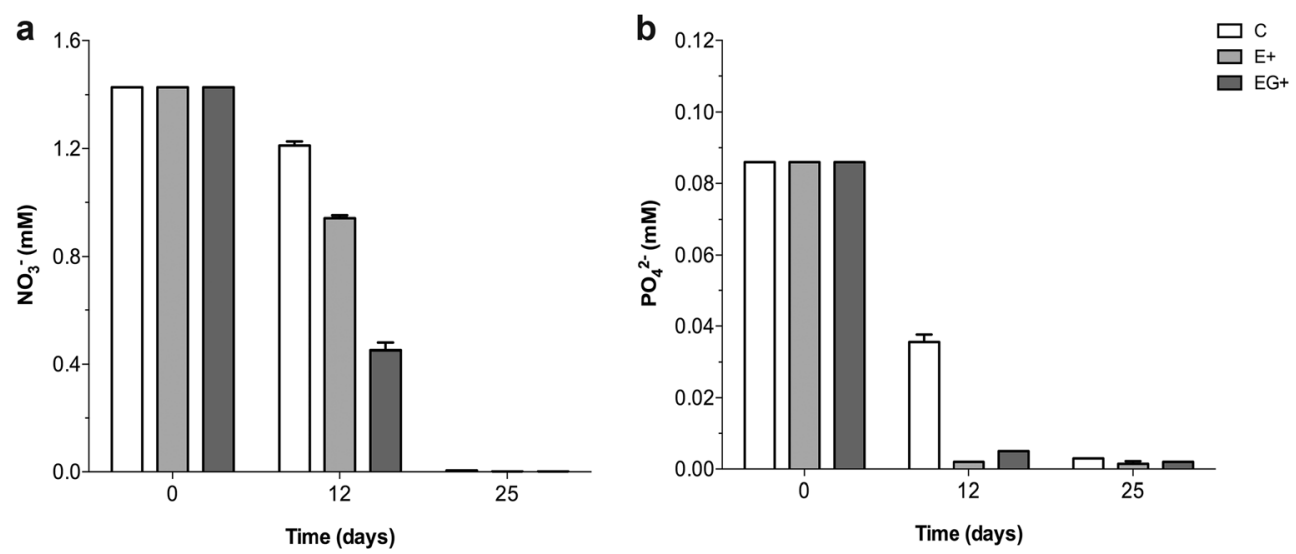

Fig. 4 Time course variations in the concentrations of nitrate (a) and of phosphate (b) in culture media of Neochloris oleoabundans during 25 days of cultivation on $\mathrm{BM}$ medium (white), $\mathrm{E}+$ medium (light gray), and $\mathrm{EG}+$ medium (dark gray). Values are means $\pm \mathrm{SD}(n=3)$ 
observed for all samples, without significant differences between $\mathrm{C}$ and $\mathrm{E}+$ samples (Fig. 5b). Similar to Chla content, $\mathrm{EG}+$ cells contained lower quantities of $\mathrm{Chl} b$ than $\mathrm{C}$ and $\mathrm{E}+$ samples (15-25 and 20-35\% lower than $\mathrm{C}$ and $\mathrm{E}+$ samples, respectively). More evident differences were observed for $\mathrm{Car}$ content (Fig. 5c). In fact, $\mathrm{C}$ samples showed an evident increase up to the end of the experiment, always containing higher quan-tities compared with the other samples (20-45 and 15-30\%more than $\mathrm{E}+$ and $\mathrm{EG}+$ samples, respectively; $p<0.05$ ). It is noteworthy that $\mathrm{EG}+$ and $\mathrm{E}+$ cells shared a similar trend of $\mathrm{Car}$ concentration during the experiment (Fig. 5c).

\section{Maximum quantum yield of PSII of $N$. oleoabundans cultivated in exhausted and control media}

The variations in PSII maximum quantum yield measured during the experiments are shown in Fig. 6. C, E+, and EG+ samples showed a slight increase of the $F_{\mathrm{V}} / F_{\mathrm{M}}$ ratio during the first 3 days of growth, reaching values of ca. 0.70. Subsequently, C cells maintained stable values around 0.70 0.75 , while the $F_{\mathrm{V}} / F_{\mathrm{M}}$ ratio of $\mathrm{E}+$ and $\mathrm{EG}+$ samples decreased drastically down to values below 0.50 at the end of experiment. In EG+ cells, the decrease was dramatic already from the 3rd day of cultivation, reaching the lowest value after 17 days (ca. 0.30 for $\mathrm{EG}+$ vs 0.75 for $\mathrm{C}$ and 0.50 for $\mathrm{E}+; p$ $<0.01$ in both cases); thereafter, samples maintained stable values of ca. 0.35 until the end of the experiment. On the contrary, in E+ cells, $F_{\mathrm{V}} / F_{\mathrm{M}}$ started to decrease very strongly only from the 7th day of cultivation until the 17th day (from about 0.70 at day 7 down to 0.50 at day 17). During the subsequent experimental times (21th and 25th day), the $F_{\mathrm{V}} / F_{\mathrm{M}}$ ratio of $\mathrm{E}+$ cells remained stable around 0.45 .

\section{Morphological observations of $N$. oleoabundans cultivated in exhausted and control media}

\section{Light microscopy and Nile red staining}

Light microscopy of both control and treated samples showed that $N$. oleoabundans maintained similar cell morphology and dimensions throughout the experiment (Figs. 7 and 8). In fact, cells were almost spherical with a cell diameter of 3-5 $\mu \mathrm{m}$. One cup-shaped chloroplast, containing a large pyrenoid, was present inside the cells (Fig. 7a, c, and e). Moreover, the chlo-roplast emitted an intense red fluorescence due to Chl (Fig. 7b, d, and f). Interestingly, after 25 days of cultivation, while cell size and shape remained substantially unchanged, all algal

Fig. 5 Time course variations of Chl $a$ (a), Chl $b$ (b), and Car content in Neochloris oleoabundans cells grown in BM (filled circles), E+ (empty squares) and $\mathrm{EG}+$ (empty diamonds) media during the 25 days of culti vation. Values are means $\pm \mathrm{SD}(n=3)$
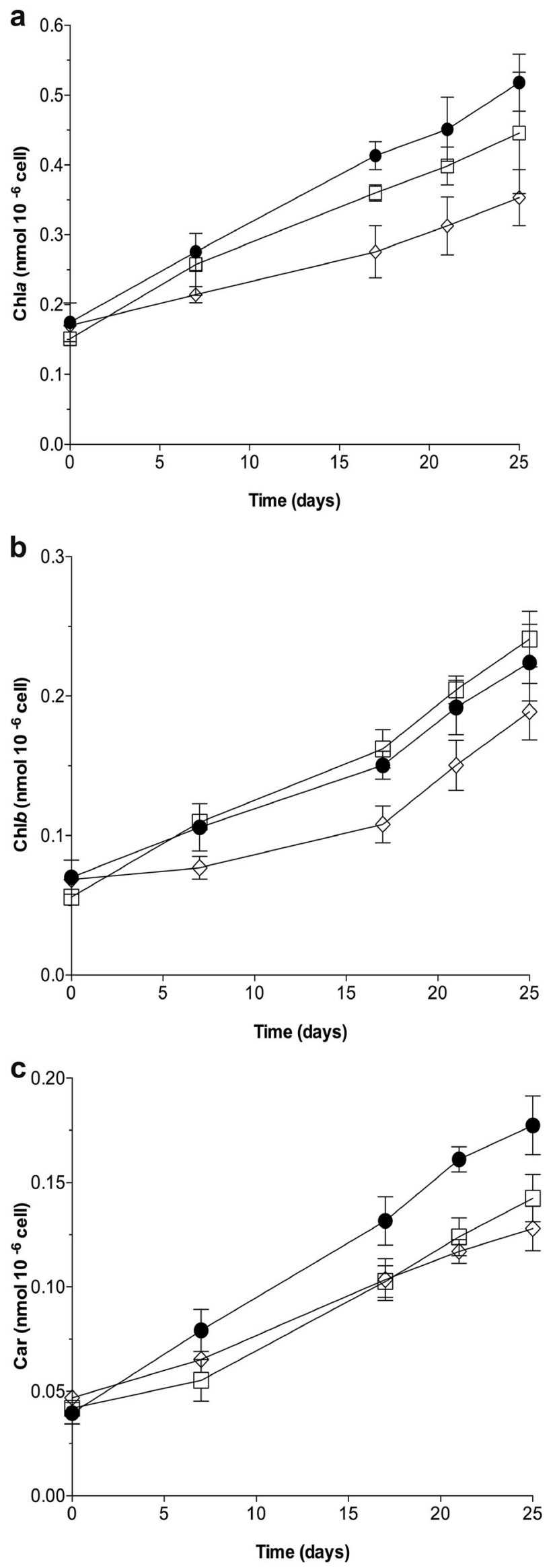


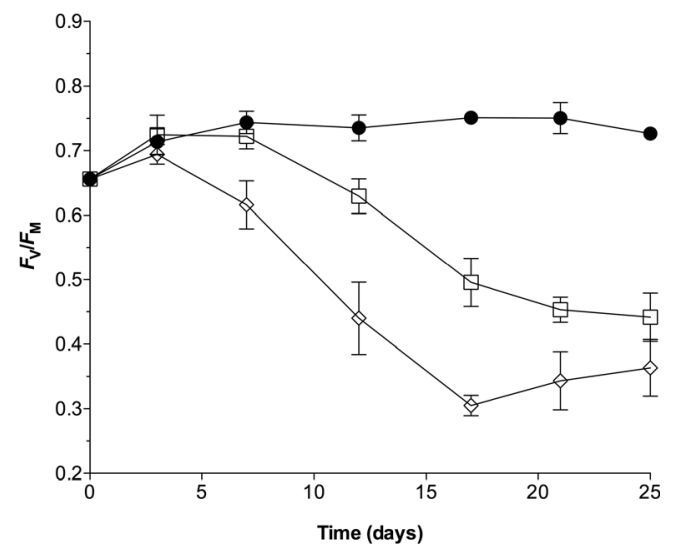

Fig. 6 Time course variations of PSII maximum quantum yield $\left(F_{\mathrm{V}} /\right.$ $F_{\mathrm{M}}$ ratio) in Neochloris oleoabundans cells grown in BM (filled circles), $\mathrm{E}+$ (empty squares), and $\mathrm{EG}+($ empty diamonds) media during the 25 days of cultivation. Values are means $\pm \mathrm{SD}(n=3)$

samples showed some translucent granulation at the cytoplasmic level (Fig. 8a, c, and e). In order to understand the nature of those granulations and to investigate if the recycled growth media could promote the production of lipid globules, all samples were periodically stained with the lipid-specific fluorochrome Nile red. The reaction was positive only at the end of the experiment, and the translucent globules were then unequivocally identified as lipid droplets (Fig. 8b, d, and f).

\section{TEM observations}

To investigate the morphological and cytological changes in-duced by cultivation in recycled growth media, the ultrastruc-ture of $\mathrm{C}, \mathrm{E}+$, and $\mathrm{EG}+$ samples was observed by TEM. At 12 days of cultivation, most of the $\mathrm{C}$ cell volume was occupied by a characteristic cup-shaped chloroplast. Inside the plastid, one large pyrenoid, which was crossed by two elongated and appressed thylakoids, was present (Fig. 9a). In particular, the organelle contained starch in the shape of a shell around the pyrenoid and showed the typical thylakoid organization (Fig. 9b). Typically featured chloroplasts, as described for cells grown in $\mathrm{C}$, were observed in cells grown in $\mathrm{E}+$ medium (Fig. 9c); however, thylakoids were more appressed than in C (Fig. 9d). EG+ samples showed a more strongly altered chloroplast structure (Fig. 9e), as compared with $\mathrm{C}$ and $\mathrm{E}+$ sam-ples. Photosynthetic membranes showed different degrees of thylakoid appression: some portions of thylakoid membranes were appressed while others were loose and sometimes swol-len (Fig. 9f, g). In addition, large portions of the stroma were free of thylakoids and some plastoglobules in proximity of the thylakoid membranes were also visible (Fig. 9g, h). Finally, in EG+ samples, the pyrenoid lost its round shape and appeared malformed (Fig. 9e).
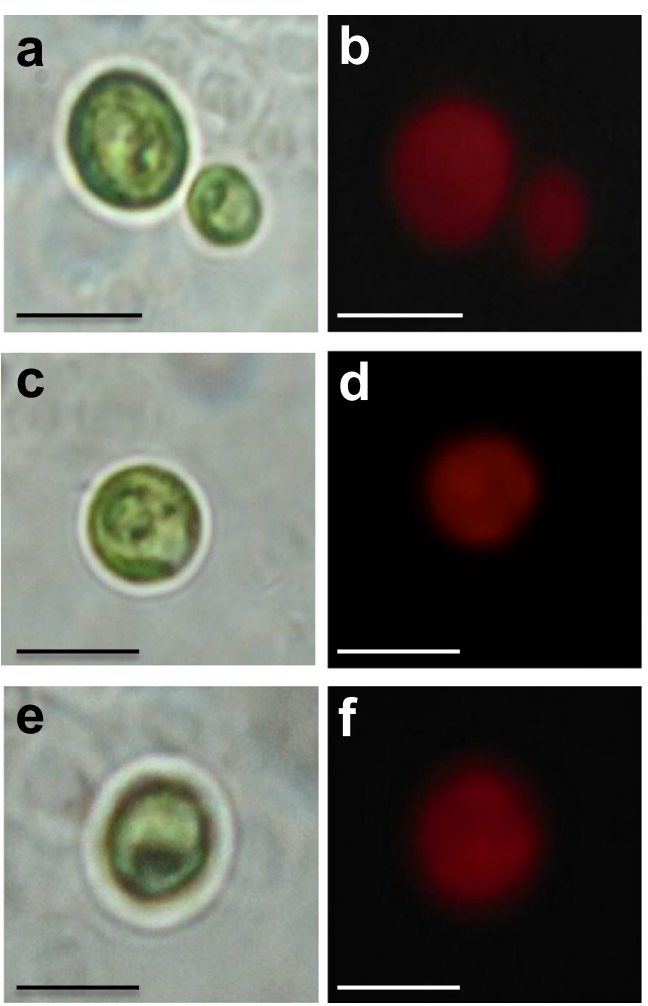

Fig. 7 Light and fluorescence microscopy observations of Neochloris oleoabundans cells at 12 days of cultivation. a Control cells and $\mathbf{b}$ the relative fluorescence of the chloroplast; $\mathbf{c}$ cell grown in $\mathrm{E}+$ medium and d the relative fluorescence of the chloroplast; e cell grown in EG+ medium and $\mathbf{f}$ the relative fluorescence of the chloroplast. In all micrographs, bars $=2 \mu \mathrm{m}$

\section{Discussion}

The recycling of culture medium has been proposed as a pos-sible solution in order to reduce water consumption for algal cultivation, thereby making the process more economically feasible and environmentally sustainable (Yang et al. 2011; Hadj-Romdhane et al. 2013; Farooq et al. 2014). Yang et al.(2011) estimated that the large-scale cultivation of the microalga Chlorella vulgaris in recycled culture medium could reduce water use by about $84 \%$. Present results clearly suggest that $N$. oleoabundans can also efficiently grow in exhausted growth media, especially in the autotrophic medi-um replenished with nitrate and phosphate $(\mathrm{E}+)$. Observing the consumption trend of these main nutrients (Fig. 4), it is clear that in the exhausted media their concentration decreased faster with respect to controls in parallel to the enhanced cell growth. Moreover, phosphate was consumed faster than ni-trate by all samples, probably because of its 100 times lower concentration with respect to the latter nutrient $\left(0.2 \mathrm{~g} \mathrm{~L}^{1}\right.$ of nitrate vs $0.002 \mathrm{~g} \mathrm{~L}^{1}$ of phosphate; Baldisserotto et al. 2012).Thus, in order to make the use of a recycled culture medium feasible, exhausted media should be replenished with 

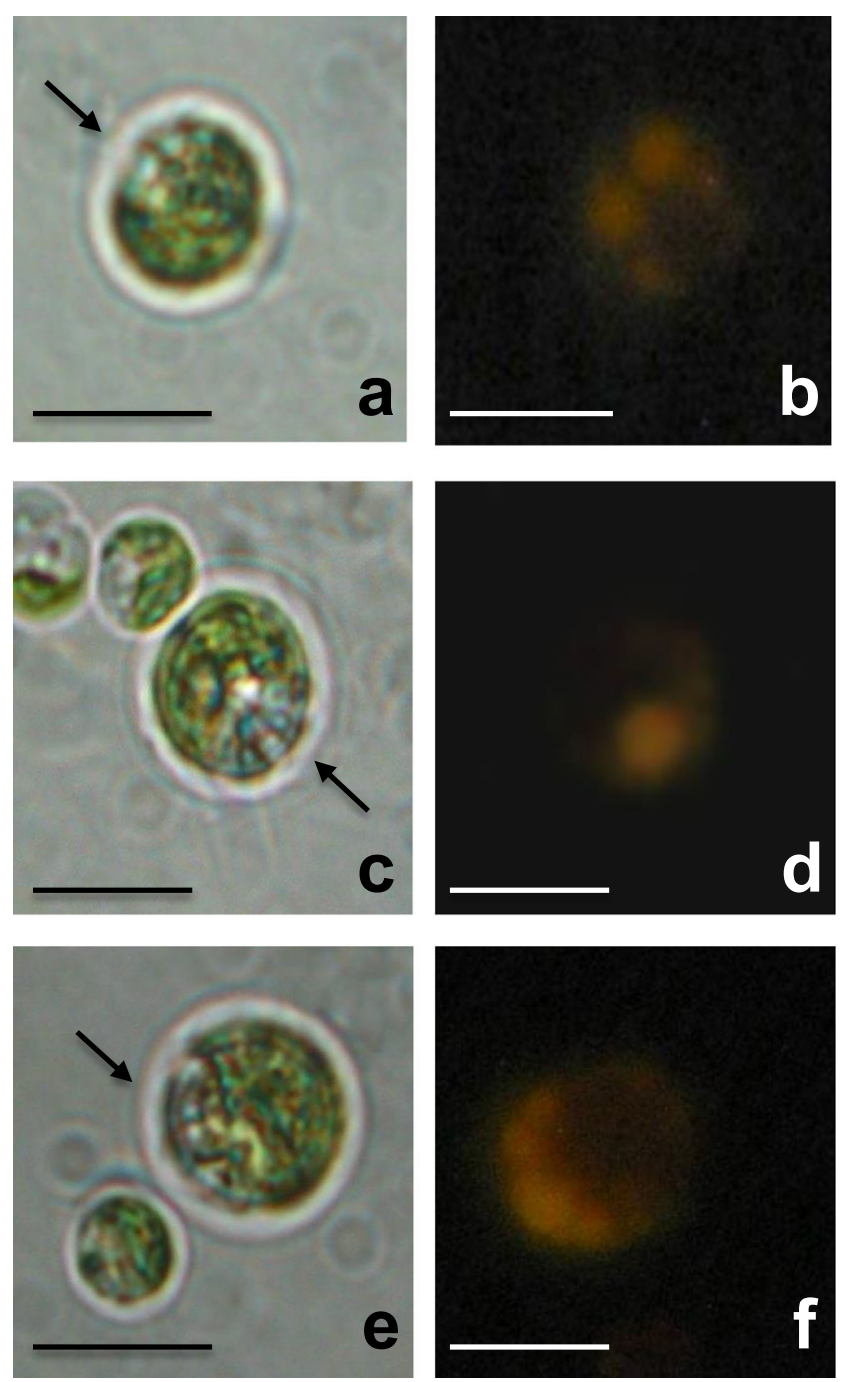

Fig. 8 Light and epifluorescence pictures of Neochloris oleoabundans cells after 25 days of growth. a Control cells and $\mathbf{b}$ relative Nile red staining observation, $\mathbf{c}$ cells grown in $\mathrm{E}+$ medium and $\mathbf{d}$ relative Nile red staining observation, and $\mathbf{e}$ cells grown in $\mathrm{E}+$ medium and $\mathbf{f}$ relative Nile red staining observation in EG+ medium. Translucent globules are indicated with arrows. In all micrographs, bars $=2 \mu \mathrm{m}$

the correct ratio of nitrate and phosphate, as they are the main nutrients that guarantee cell growth (Stephens et al. 2010). This aspect was preliminarily verified by employing unmod-ified exhausted growth media (E and $\mathrm{EG}$ ) to recultivate $N$. oleoabundans. In fact, cells showed a slight growth, reaching, at the end of the cultivation period, low cell densities (ca. $11 \mathrm{vs} 32 \times 10^{6}$ cells $\mathrm{mL}^{1}$ of $\mathrm{C}$ cultures) (data not shown). These cells accumulated intracellular lipids throughout the experiment (data not shown) as a consequence of the limita-tion of nitrate and phosphate (Mata et al. 2010; Popovich et al. 2012). These results are consistent with those of Zhu et al.(2013), who found that C. zofingensis cultivated in recycled medium, without nitrogen and phosphorus, displayed en-hanced lipid production compared with cultures with full nutrients.
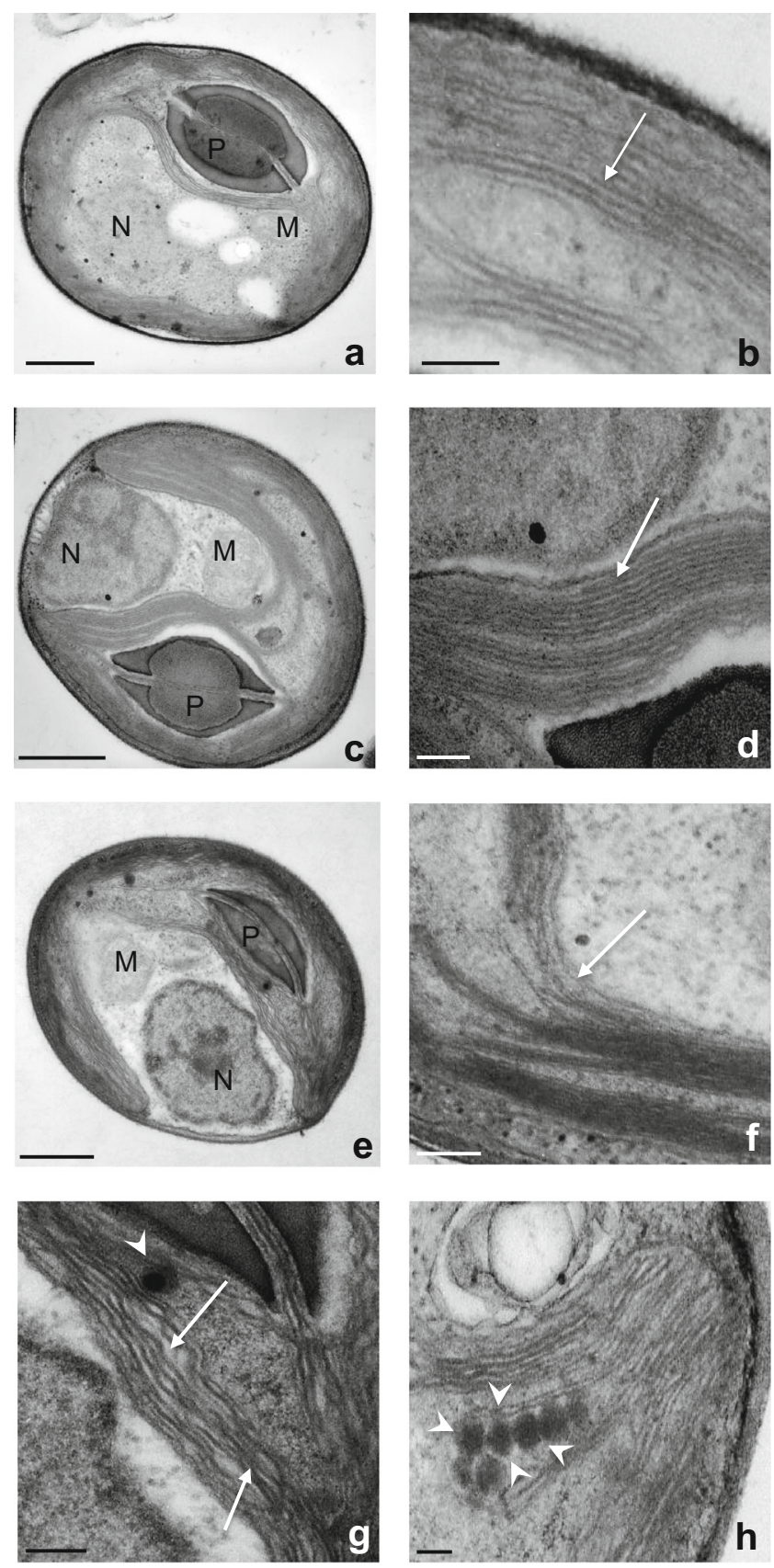

Fig. 9 Transmission electron micrographs of Neochloris oleoabundans cells at 12 days of cultivation. a Cell grown in BM medium and $\mathbf{b}$ detail of its chloroplast showing the typical thylakoid membranes organization (white arrow). c Cell grown in $\mathrm{E}+$ medium and $\mathbf{d}$ detail of its chloroplast with quite compact and appressed (white arrow) thylakoids. e Cell grown in EG+ medium and $\mathbf{f} \mathbf{h}$ details of its chloroplast. The presence of intermediate stages of thylakoid membranes are evident in EG+ cells, showing a general disorganization of thylakoid membranes ( $f$ h), which appeared wavy, loose, and sometimes swollen (f, g). h Some plastoglobules in proximity of thylakoid membranes are also observed (arrowheads). $P$ pyrenoid, $N$ nucleus, $M$ mithochondrion. Bars, $0.5 \mu \mathrm{m}$ $(\mathbf{a}, \mathbf{c}, \mathbf{e})$ and $0.05 \mu \mathrm{m}(\mathbf{b}, \mathbf{d}, \mathbf{f}, \mathbf{g}, \mathbf{h})$

In order to understand if the growth promotion of $N$. oleoabundans cultivated in $\mathrm{E}+$ and $\mathrm{EG}+$, relative to $\mathrm{C}$, was influenced by some molecules released from the algae, 
a characterization of autotrophic (E) and mixotrophic (EG) media was performed. First of all, $\mathrm{pH}$ of the control and exhausted media was monitored. In particular, an increasing trend was observed in control, which reached the $\mathrm{pH}$ of the exhausted media at the end of the experiment. This was not surprising, considering that during the microalgal growth, $\mathrm{pH}$ usually increases because of the consumption of $\mathrm{CO}_{2}$ during the photosynthetic process (Zhang et al. 2014). However, considering that in $\mathrm{E}^{+}$and $\mathrm{EG}^{+} \mathrm{pH}$ fluctuated around their initial values, or at least gradually decreased, it is not possible to attribute to $\mathrm{pH}$ any evident role in the cell growth promotion. Moheimani and Borowitzka (2006) and Stephens et al. (2010) reported that molecules released from cells can positively/ negatively alter cell metabolism and biomass production.

Here we show that both exhausted media contained the main PAs (putrescine, spermidine, and spermine). It is known that these plant growth regulators are involved in a great variety of developmental processes in plant cells, e.g., cell division and protein synthesis (Kaur-Sawhney et al. 2003; Kuznetsova et al. 2006). PA biosynthetic pathways have also been studied in green algae (Cohen et al. 1984; Theiss et al. 2002; Fuell et al. 2010). Although algae produce "unusual" PAs, such as homospermidine and thermospermine (Hamana et al. 2013), the more common PAs (Put, Spd, and Spm), when added to the media, promoted growth and metabolism in C. vulgaris (Czerpak et al. 2003). PAs are also known to alleviate the effect of biotic and abiotic stress in plants as well as algae (Tate et al. 2013).

In the present work, a very strong increase in Put and, especially, Spd concentrations was observed in $N$. oleoabundans mixotrophic cells as compared with the autotrophic ones, both cultivated in a 20-L PBR. The growthpromoting role of PAs could explain the faster ( $0-4$ days $)$ and stronger cell density increase (ca. $33 \times 10^{6}$ cell mL ${ }^{1}$ ) in mixotrophic cultures relative to the autotrophic ones $(0-9$ days; ca. $22 \times 10^{6}$ cell $\mathrm{mL}^{1}$ ). The higher PA concentrations in mixotrophically grown cells also suggest that, under these culture conditions, algal cells may be better protected from stress-inducing factors, e.g., bacterial contamination. To our knowledge, the presence of PAs released into algal growth medium in PBRs has not been documented before. The release of PAs (predominantly Spd) from autotrophic and mixotrophic cells into their respective (E and $E G$ ) exhausted media was not significantly different. However, the presence of these plant growth regulators seems to contribute to the promotion of $N$. oleoabundans growth in both media replenished with nitrate and phosphate. In fact, during the entire experiment, a higher cell density was observed in $\mathrm{E}+$ relative to $\mathrm{C}$ medium. Moreover, the $\mathrm{EG}+$ samples showed a promotion of cell density, albeit similar to that of C.

Both autotrophic and mixotrophic exhausted media also contained FFAs, which could have induced a change in the normal metabolism of $N$. oleoabundans. This assumption is demonstrated by the more rapid consumption of nitrate and phosphate, the decreased photosynthetic pigments content and the strong decline in the $F_{\mathrm{V}} / F_{\mathrm{M}}$ ratio observed in cells grown in $\mathrm{E}+$ and $\mathrm{EG}+$ media. These results corroborate the assumption that microalgae release metabolites in high cell density cultures (Richmond 2004) or as a consequence of stressful conditions (Ikawa 2004; Wu et al. 2006). Even if the role of FFAs is currently under debate (Ikawa 2004; Stephens et al. 2010), recent studies showed that they can strongly inhibit growth or exert cytotoxic effects on microalgae (Kogteva and Bezuglov 1998; Wu et al. 2006; Bosma et al. 2008; Stephens et al. 2010). In fact, the pres-ence of these metabolites, and their oxidative products, negatively affect biomass productivity, especially when the microalgae are cultivated in recycled medium (Lívanský et al. 1996; Rodolfi et al. 2003). Granum et al.(2002) reported that the accumulation of intracellular lipids in microalgae enhanced the release of FFAs into the culture medium, and Harun et al. (2010) observed that this release was caused by cell lysis.

In this work, FFA composition in autotrophic (E) and mixotrophic (EG) media after $N$. oleoabundans cultivation was similar. The only main difference was represented by the presence of the monoenoic oleic acid (C18:1 $\omega 9)$ in EG medium. Oleic acid is one of the major lipid components in lipid-enriched $N$. oleoabundans grown under N-stress conditions (Popovich et al. 2012). It is reported that mixotrophic cultivation alters $\mathrm{N} / \mathrm{C}$ ratio, inducing similar lipid production as $\mathrm{N}$-depleted autotrophic cultures (Giovanardi et al. 2014). Probably for this reason, the release of oleic acid occurred only in the mixotrophic growth medium. Moreover, Wu et al. (2006) observed an altered plasma membrane permeability due to the toxic effects of FFAs in two Chlorophyta (C. vulgaris and Monoraphidium contortum) and in a cyanobacterium (Anabaena P-9). Then, in addition to the lower concentration with respect to nitrate in BM medium, the rapid consumption of phosphate in both exhausted media could be linked also to an alteration in membrane permeability, due to the activity of FFAs (Ikawa 2004; Wu et al. 2006). In addition, FFAs can cause inhibition of the PSII and PSI electron transport chains (Siegenthaler 1973) and disorganization of thylakoids (Wu et al. 2006). Indeed, N. oleoabundans cells in E+ and EG+ were characterized by alterations of the photosynthetic apparatus. These cells, in fact, contained less photosynthetic pigments than $\mathrm{C}$ cells and exhibited a drastic decrease of the PSII maximum quantum yield $\left(F_{\mathrm{V}} / F_{\mathrm{M}}\right)$. These variations are linked to an alteration of photosynthetic efficiency, especially as regards PSII (White et al. 2011). The decreased photosynthetic pigment contents, observed in cells grown in $\mathrm{E}+$ and $\mathrm{EG}+$, also reflected the changes in thylakoid membrane arrangement (Baldisserotto et al. 2012). Therefore, correct thylakoid organization is necessary to 
maintain optimal photosynthetic activity, and this is often influenced by culture conditions (Nevo et al. 2012). In addition, the presence of some plastoglobules in chloroplasts of algal cells, grown on exhausted media, could be another indicator of an alteration of photosynthetic membranes (Besagni and Kessler 2013). On the contra ry, $N$. oleoabundans cells grown in $\mathrm{C}$ medium showed stable and normal $F_{\mathrm{V}} / F_{\mathrm{M}}$ values throughout the experiment (Giovanardi et al. 2014), and the typical assembly of thyla-koid membranes (Nevo et al. 2012; Baldisserotto et al. 2012; Giovanardi et al. 2014).

The presence of lipid droplets, observed only at the end of the experiment in $\mathrm{C}, \mathrm{E}+$, and $\mathrm{EG}+$ cells, is probably related to aging of the microalgal cultures (Hu et al. 2008; Baldisserotto et al. 2012), rather than to the use of recycled culture media.

In conclusion, results presented here demonstrate that recycling autotrophic and mixotrophic growth media is a suitable solution to obtain high cell density cultures of the microalga $N$. oleoabundans. For this reason, they represent a contribution for improving the scale-up of microalgal cultivation while providing a more sustainable ecological impact on water resources. However, further studies are needed to deepen knowledge on the nature and the specific role of some molecules that are released into the growth media, in order to obtain useful information for the advancement of the biotechnological use of this strain.

Acknowledgments This work was financially supported by grants from the University of Ferrara. We are grateful to Dr. Immacolata Maresca of the University of Ferrara for technical assistance in freeze drying of samples.

Conflict of interest The authors declare they have no conflict of interest.

\section{References}

Baldisserotto C, Ferroni L, Giovanardi M, Pantaleoni L, Boccaletti L, Pancaldi S (2012) Salinity promotes growth of freshwater Neochloris oleoabundans UTEX 1185 (Sphaeropleales, Neochloridaceae): morpho physiological aspects. Phycologia 51: 700710

Baldisserotto C, Giovanardi M, Ferroni L, Pancaldi S (2014) Growth, morphology and photosynthetic responses of Neochloris oleoabundans during cultivation in a mixotrophic brackish medium and subsequent starvation. Acta Physiol Plant 36:461 472

Batan L, Quinn CJ, Bradley TH (2013) Analysis of water footprint of a photobioreactor microalgae biofuel production system from blue, green and lifecycle perspectives. Algal Research 2:196 203

Besagni C, Kessler F (2013) A mechanism implicating plastoglobules in thylakoid disassembly during senescence and nitrogen starvation. Planta 237:463 470

Borowitzka MA (2005) Culturing microalgae in outdoor ponds. In: Anderson RA (ed) Algal culturing techniques. Elsevier Academic, London, pp. 205218
Borowitzka MA, Moheimani NR (2013) Sustainable biofuels from algae. Mitig Adapt Strateg Glob Change 18:13 25

Bosma R, Miazek K, Willemsen SM, Vermuë MH, Wijffels RH (2008) Growth inhibition of Monodus subterraneus by free fatty acids. Biotechnol Bioeng 101:1108 1114

Chisti Y (2007) Biodiesel from microalgae. Biotech Adv 25:294 306

Czerpak R, Bajguz A, Pietrowska A, Dobrogowska R, Matejczyk M, Weislawski W (2003) Biochemical activity of di and polyamines in the green alga Chlorella vulgaris Beijerinck (Chlorophyceae). Acta Soc Bot Pol 72:19 24

Cohen E, Arad SM, Heimer YH, Mizrahi Y (1984) Polyamine biosyn thetic enzymes in the cell cycle of Chlorella. Plant Physiol 74:385 388

Farooq W, Suh WI, Park MS, Yang J (2014) Water use and its recycling in microalgae cultivation for biofuel application. Bioresource Technol. doi:10.1016/j.biortech.2014.10.140

Ferroni L, Baldisserotto C, Giovanardi M, Pantaleoni L, Morosinotto T, Pancaldi S (2011) Revised assignment of room temperature chloro phyll fluorescence emission bands in single living cells of Chlamydomonas reinhardtii. J Bioenerg Biomembr 43:163 173

Fuell C, Elliott KA, Hanfrey CC, Franceschetti M, Michael AJ (2010) Polyamine biosynthetic diversity in plants and algae. Plant Physiol Biochem 48:513 520

Giovanardi M, Ferroni L, Baldisserotto C, Tedeschi P, Maietti A, Pantaleoni L, Pancaldi S (2013) Morpho physiological analyses of Neochloris oleoabundans (Chlorophyta) grown mixotrophically in a carbon rich waste product. Protoplasma 250:161 174

Giovanardi M, Baldisserotto C, Ferroni L, Longoni P, Cella R, Pancaldi S (2014) Growth and lipid synthesis promotion in mixotrophic Neochloris oleoabundans (Chlorophyta) cultivated with glucose. Protoplasma 251:115 125

Gouveia L, Marques AE, Lopes da Silva T, Reis A (2009) Neochloris oleoabundans UTEX \#1185: a suitable renewable lipid source for biofuel production. J Ind Microbiol Biotechnol 36:821 826

Granum E, Kirkvold S, Myklestad SM (2002) Cellular and extracellular production of carbohydrates and amino acids by the marine diatom Skeletonema costatum: diel variations and effects of $\mathrm{N}$ depletion. Mar Ecol Prog Ser 242:83 94

Grobbelaar JU (2009) Factors governing algal growth in photobioreactors: the "open" versus "closed" debate. J Appl Phycol 21:489 492

Hadj Romdhane F, Jaouen P, Pruvost J, Grizeau D, Van Vooren G, Bourseau P (2012) Development and validation of a minimal growth medium for recycling Chlorella vulgaris culture. Bioresource Technol 123:366 374

Hadj Romdhane F, Zheng X, Jaouen P, Pruvost J, Grizeau D, Croué JP, Bourseau P (2013) The culture of Chlorella vulgaris in a recycled supernatant: effects on biomass production and medium quality. Bioresource Technol 132:285 292

Hamana K, Niitsu M, Hayashi H (2013) Occurrence of homospermidine and thermospermine as a cellular polyamine in unicellular chlorophyte and multicellular charophyte green algae. J Gen Appl Microbiol 59:313 319

Harun R, Singh M, Forde GM, Danquah MK (2010) Bioprocess engi neering of microalgae to produce a variety of consumer products. Renew Sust Energ Rev 14:1037 1047

Hu Q, Sommerfeld M, Jarvis E, Ghirardi M, Posewitz M, Seibert M, Darzins A (2008) Microalgal triacylglycerols as a feedstocks for biofuel production: perspective and advances. Plant J 54:621 639

Ikawa M (2004) Algal polyunsaturated fatty acids and effects on plankton ecology and other organism. UNH Center for Freshwater Biology Research 6:17 44

Kalaji HM, Schansker G, Ladle RJ, Vasilij Goltsev V, Bosa K, Allakhverdiev SI, Brestic M, Bussotti F, Calatayud A, Dąbrowski P, Elsheery NI, Ferroni L, Guidi L, Hogewoning SW, Jajoo A, Misra AN, Nebauer SG, Pancaldi S, Penella C, Poli D, Pollastrini M, 
Romanowska Duda ZB, Rutkowska B, Serôdio J, Suresh K, Szulc W, Tambussi E, Yanniccari M, Zivcak M (2014) Frequently asked questions about in vivo chlorophyll fluorescence: practical issues. Photosynth Res 122:121 158

Kaur Sawhney R, Tiburcio AF, Altabella T, Galston AW (2003) Polyamines in plants: an overview. J Cell Mol Biol 2:1 12

Kogteva GS, Bezuglov VV (1998) Unsaturated fatty acids as endogenous bioregulators. Biochem Mosc 63:4 12

Lam MK, Lee KT (2012) Potential of using organic fertilizer to cultivate Chlorella vulgaris for biodiesel production. Appl Energy 94:303 308

Li Y, Horsman M, Wang B, Wu N, Lan CQ (2008) Effect on nitrogen sources on cell growth and lipid accumulation of green alga Neochloris oleoabundans. Appl Microbiol Biotechnol 81: 629636

Lichtenthaler HK, Buschmann C, Knapp M (2005) How to correctly determine the different chlorophyll fluorescence parameters and the chlorophyll fluorescence decrease ratio RFd of leaves with the PAM fluorometer. Photosynthetica 43:379 393

Lívanský K, Dědič K, Bínová J, Tichý V, Novotný P, Doucha J (1996) Influence of the nutrient solution recycling on the produc tivity of Scenedesmus obliquus, utilization of nutrients and water in outdoor cultures. Algological Studies/Archiv für Hydrobiologie 81:105 113

Mata TM, Martins AA, Caetano NS (2010) Microalgae for biodiesel production and other applications: a review. Renew Sust Energ Rev 14:217 232

Moheimani NR, Borowitzka MA (2006) (2006) the long term culture of the coccolithophore Pleurochrysis carterae (Haptophyta) in outdoor raceway ponds. J Appl Phycol 18:703 712

Molina Grima E, Belarbi H, Acién Fernández FG, Robles Medina A, Chisti Y (2003) Recovery of microalgal biomass and metabolites: process options and economics. Biotech Adv 20:491 515

Ndimba BK, Ndimba RJ, Johnson TS, Waditee Sirisattha R, Baba M, Sirisattha S, Shiraiwa Y, Rakwal R, Agrawal GK, Rakwal R (2013) Biofuels as a sustainable energy source: an update of the applications of proteomics in bioenergy crops and algae. J Prot 93: 234244

Nevo R, Charuni D, Tsabari O, Reich Z (2012) Composition, architecture and dynamics of the photosynthetic apparatus in higher plants. Plant J 70:157 176

Pancaldi S, Baldisserotto C, Ferroni L, Bonora A, Fasulo MP (2002) Room temperature microspectrofluorimetry as a useful tool for studying the assembly of the PSII chlorophyll protein complexes in single living cells of etiolated Euglena gracilis Klebs during the greening process. J Exp Bot 53:1753 1763

Popovich CA, Damiani MC, Constenla D, Martínez AM, Giovanardi M, Pancaldi S, Leonardi PI (2012) Neochloris oleoabundans grown in natural enriched seawater for biodiesel feedstock: evaluation of its growth and biochemical composition. Bioresource Technol 114: 287293

Pruvost J, Van Vooren G, Cogne G, Legrand J (2009) Investigation of biomass and lipids production with Neochloris oleoabundans in photobioreactor. Bioresource Technol 100:5988 5995
Pulz O (2001) Photobioreactors: production systems for phototrophic microorganisms. Appl Microbiol Biotechnol 57:287 293

Richmond A (2004) Handbook of microalgal culture: biotechnology and applied phycology. Blackwell Sciences Ltd., Oxford

Rodolfi L, Zittelli GC, Barsanti L, Rosati G, Tredici MR (2003) Growth medium recycling in Nannochloropsis sp. mass cultivation. Biomol Eng 20:243 248

Scaramagli S, Biondi S, Capitani F, Gerola P, Altamura MM, Torrigiani P (1999) Polyamine conjugate levels and ethylene biosynthesis: in verse relationship with vegetative bud formation in tobacco thin layers. Physiol Plant 105:366 375

Sheehan JJ (2009) Biofuels and the conundrum of sustainability. Curr Opin Biotechnol 20:318 324

Siegenthaler PA (1973) Change in $\mathrm{pH}$ dependence and sequential inhibi tion of photosynthetic activity in chloroplasts by unsaturated fatty acids. Biochim Biophys Acta 305:153 162

Smith VH, Sturm BSM, deNoyelles FJ, Billings SA (2010) The ecology of algal biodiesel production. Trends Ecol Evo 25:301 309

Solomon BD (2010) Biofuels and sustainability. Ann N Y Acad Sci 1185: 119134

Stephens E, Ross IL, Mussgnug JH, Wagner LD, BorowitzkaMA PC, Kruse O, Hankamer B (2010) Future prospects of microalgal biofuel production systems. Trends Plant Sci 15:554 564

Tate JJ, Gutierrez Wing MT, Rush KA, Benton MG (2013) The effects of plant growth substances and mixed cultures on growth and metab olite production of green algae Chlorella sp.: a review. J Plant Growth Regul 32:417 428

Tornabene TG, Holzer G, Lien S, Burris N (1983) Lipid composition of the nitrogen starved green alga Neochloris oleoabundans. Enzyme Microbiol Tech 5:435 440

Theiss C, Bohley P, Voigt J (2002) Regulation by polyamines of ornithine decarboxylase activity and cell division in the unicellular green alga Chlamydomonas reinhardtii. Plant Physiol 128:1470 1479

Wellburn AR (1994) The spectral determination of chlorophylls a and b, as well as total carotenoids, using various solvents with spectropho tometer of different resolution. J Plant Physiol 144:307 313

White S, Anandraj A, Bux F (2011) PAM fluorometry as a tool to assess microalgal nutrient stress and monitor cellular neutral lipids. Bioresource Technol 102:1675 1682

Wu JT, Chiang YR, Huang WY, Jane WN (2006) Cytotoxic effects of free fatty acids on phytoplankton algae and cyanobacteria. Aquat Toxicol 80:338 345

Yang J, Xu M, Zhang X, Hu Q, Sommerfeld M, Chen Y (2011) Lifecycle analysis on biodiesel production from microalgae: water footprint and nutrients balance. Bioresource Technol 102:159 165

Zhang Q, Wang T, Hong Y (2014) Investigation of initial pH effects on growth of an oleaginous microalgae Chlorella sp. HQ for lipid and nutrient uptake. Water Sci Technol 70:712 719

Zhu LD, Takala J, Hiltunen E, Wang ZM (2013) Recycling harvest water to cultivate Chlorella zofingiensis under nutrient limitation for bio diesel production. Bioresource Technol 144:14 20 